\title{
Landscape change under the surface water allocation in Ejina oasis, northwestern China
}

\author{
$\mathrm{CAO} \mathrm{Yu}^{1}$ \\ Department of Land Management \\ Zhejiang University \\ Hangzhou 310029, China \\ ZHANG Yangjian ${ }^{3}$ \\ Key Laboratory of Ecosystem Network \\ Observation and Modeling \\ Institute of Geographical Sciences and Natural \\ Resources Research, Chinese Academy of \\ Sciences \\ Beijing 100101, China
}

\author{
WU Yuhuan ${ }^{2}$ \\ College of Biological and Environmental Sciences \\ Hangzhou Normal University \\ Hangzhou 310036, China \\ TIAN Jie ${ }^{4}$ \\ Department of International Development, \\ Community, and Environment, \\ Clark University \\ Worcester, MA 01610, USA
}

\begin{abstract}
Exploring the relationships, which are strictly influenced by water resource conditions, between oasis landscape pattern and hydro-ecological process in arid area, becomes the hot topic and difficult challenge in arid landscape ecology and one of the most important issues in arid areas ecological protection and reconstruction. The Heihe river basin, as the ${ }^{2}$ nd longest inland river basin, is located in the northwest arid regions of China. During the past few decades before 2001, increasing local population and social-economic development in the upper reaches of Heihe river basin have consumed surface water resource enormously. Consequently, a lot of serious ecological and environmental problems were occurred in the Ejina natural oasis, which is in lower reaches of Heihe river basin. Especially, the Ejina natural oasis was in face of disappearing in the world with no surface water provided from the upper reaches for continuous several years around 2001. From the beginning of 2001, appropriate amount of surface water has been allotted to Ejina oasis from the upper reaches by the Chinese government every year to prevent the rigorously ecological crisis continuing and retrieve the environment restoring. Based on field investigation, remote sensing, and GIS technologies, Ejina natural oasis landscape spatial pattern and its dynamic change in different temporal and spatial scale before and after surface water allotted (1987 2001 2009) were analyzed in this paper. Three Landsat TM/ETM+ images in 1987, 2001 and 2009 were collected to analysis the characteristics of oasis landscape spatial pattern dynamics over the past few decades. The main results show that: before and after water resource allocated, the area of oasis classes decreased during 1987-2001 and increased during 2001-2009, but simultaneously the desert classes changed to an inverse direction; the landscape diversity and ecological stability for Ejina oasis after water allocated was much higher than before water allocated.
\end{abstract}

Key words-Landscape spatial pattern change, APACK, surface water allotting, Ejina natural oasis, Northwestern China.

\section{INTRODUCTION}

With the development of sciences and technologies and the rapid increasing world populations, the degree of human activities are getting more and more serious, and the influences of mankind has become the key factor to drive modern landscape change in the earth ${ }^{[1,2]}$. Integrating the aspects of human activity into the research fields of landscape ecology also became one of the most important challenges and issues in modern earth sciences. As an interdisciplinary subject of geography, ecology, biology and related environmental sciences subjects, landscape ecology is the science of studying landscape pattern (i.e. spatial structure), landscape process (i.e. ecological function) and the dynamics of landscape pattern and process over time driving by physical elements and human activities. As the hot topics on interpreting the relationship between landscape pattern and ecological process in landscape ecology, studies on the characteristics of landscape dynamic changes could well reveal the mechanism of landscape evolvement, evaluate ecosystem service function and simulate the trend of ecological process ${ }^{[3,4,5]}$. In arid regions on the earth, water resource is the elemental driving force for all ecological processes. Meanwhile, water is also one of the most active factors in arid environments. Owing extremely uneven distributing of water resource in spatial scale, two kinds of quite different landscapes of oasis and desert could exist synchronously in arid environments. As the special synthesis of man and nature, oasis landscape is not only the main area of human activities, but also the most ecologically sensitive area, especially influenced by water factor. Therefore, the dynamics of oasis landscape are obviously affected by the local conditions of water resources. This study will focus on the analysis of landscape spatial pattern changes for Ejina natural oasis landscape under the policy of the surface water allocation in Heihe river basin. The Heihe river is the ${ }^{2}$ nd longest arid inland river in China. During the past few decades, especially before 2000, increasing local populations and social-economic development resulted in sharp reduce of water resource. Consequently, a lot of serious ecological and environmental problems occurred throughout the watershed. Especially for the Ejina natural oasis, which is in lower

This study was supported by the Project of National Natural Science Foundation of China (NSFC, NO.30700098, NO.30970188), the Project of Zhejiang Provincial Natural Science Foundation of China (NO.Y507207), the Fundamental Research Funds for the Central Universities and Qianjiang Telents Program, Zhejiang Province (NO.QJC1302005). 
reaches of Heihe river basin, and it was dying because of no water resource distributed from the upper reaches for several years ${ }^{[6]}$. To prevent the ecological crisis from continuing and retrieve the environment recovering, Bureau of Heihe River Basin Water Resource Management was established directly by Chinese Central Government in 1999. Since 2000, appropriate amount of water resource have been allocated to Ejina natural oasis from the upper reaches of Heihe river basin by the bureau. Till 2009, almost ten years has passed, what has happened for Ejina natural oasis? How did human activities influence the ecological effects in Heihe river basin? And what's the relationship between natural oasis landscape pattern dynamics and hydro-ecological processes in human-dominated watershed? All above questions could be answered by investigating this area. This area could definitely provide an ideal site to facilitate interdisciplinary research on the relationship between water and water-related natural systems and human society. Therefore, this study will aim at the landscape spatial pattern changes which have been extensively modified by human activities, interpret the relationship between human activity (that is program of surface water allocation launched by government) and the ecological response of the natural environment (that is natural oasis landscape dynamics).

\section{MATERIALS AND METHODS}

\section{A. Study area}

The Heihe river is rising from the southern Qilian Mountains, Tibet plateau and is flowing northward to Juyan lakes in Ejina oasis (Fig. 1). The overall length and watershed area of Heihe river is about 821 kilometer and 143,000 square kilometer respectively. Before 2001, especially during 1980s 2000, owing to the uneven surface water distribution over the entire watershed, the whole Heihe river basin was facing increasing environmental problems and ecological degradation. Especially for the area of the lower reaches of Heihe river basin, the Ejina natural oasis is at the edge of disappearing. The study area of Ejina oasis is a natural oasis with about 30,000 square kilometer located in lower reaches of Heihe river basin. It has a typical continental climate with about 40 millimeter annual precipitation and about 3,500 millimeter annual evaporation. So it is a typical arid region with high evaporation and little rainfall. There are two major branches of Heihe river in Ejina oasis, one is the West Ejina river flowing to West Juyan Lake and the other is the East Ejina river flowing to East Juyan Lake.

Facing degradation and desertification of Ejina oasis, the Chinese government had carried out a strategy of surface water allocation in the Heihe river watershed. An official department of Heihe Watershed Management Bureau was established in 1999. The Bureau launched the first water allocation in 2000, the core Ejina oasis was irrigated for the first time in 2001. And the East Juyan Lake and West Juyan Lake were firstly filled in 2002 and 2003 respectively. Since August, 2004, till present, East Juyan Lake has gained and maintained about 40 square kilometer water area. Before and after the surface water was allocated from the upper reaches of
Heihe river, the local ecological conditions, especially for the water resources, were quiet different.

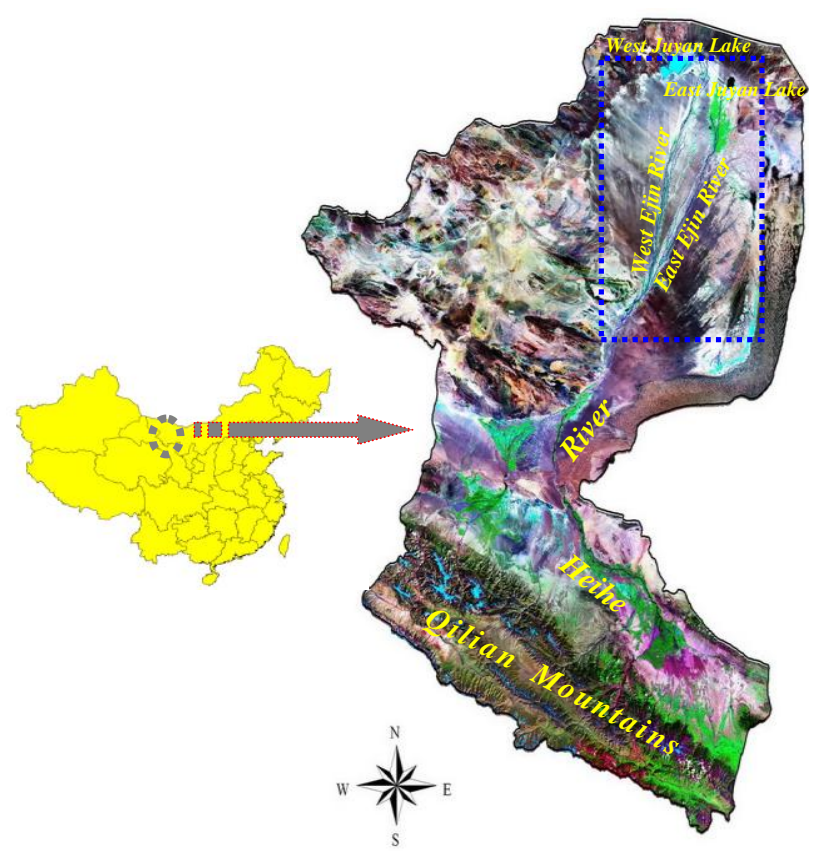

Fig. 1. The location of the Ejina oasis in lower reaches of Heihe river basin, northwestern China

\section{B. Data source}

Three Landsat TM/ETM+ images in 1987, 2001 and 2009 were collected to analyze the characteristics of oasis landscape spatial pattern dynamics over the past few decades. In addition, the statistical annual runoff data (1987 2009) prepared by Water Conservation Bureau of Ejina Banner were collected to explore the relationship between the oasis landscape pattern change and annual surface water allocation quantity.

\section{Landscape pattern analysis}

Based on remote sensing images, three landscape types and ten landscape classes were classified as the dominate land use type: oasis landscape (dominated by riparian forest, riparian shrub, water, saline and urban area), desert landscape (dominated by desert shrub, desert grassland, Gobi and sand) and others (i.e. hills and dried lake) (Table I). The spatial pattern analysis was performed based on the landscape maps in 1987, 2001 and 2009 using the APACK software package. APACK is a program that can calculate statistics of landscape spatial pattern from raster data. Basic area measures and some selected landscape indices such as Average area per patch (AA), Contagion (CO), Dominance (DO), Edge density (ED), Shannon-Weaver diversity (SWD) and Shannon-Weaver Evenness (SWE) were calculated, and landscape spatial pattern changes from 1987 to 2009 were analyzed.

\section{RESULTS AND DISCUSSION}

\section{A. Statistical analysis of landscape types}

Table II is the statistics about the area and the percentage of different landscape class in Ejina oasis during past 20 years. 
TABLE I. LANDSCAPE CLASSIFICATION SYSTEM IN EJIN OASIS

\begin{tabular}{|c|c|c|}
\hline $\begin{array}{c}\text { Landscape } \\
\text { types }\end{array}$ & $\begin{array}{c}\text { Landscape } \\
\text { classes }\end{array}$ & Description \\
\hline \multirow{5}{*}{ Oasis } & $\begin{array}{l}\text { Riparian } \\
\text { forest }\end{array}$ & $\begin{array}{l}\text { Mixed forest of Populus euphratica Olive, } \\
\text { Elaeagnus angustifolia } \text { L. and Tamarix ramosissima } \\
\text { Ledeb, } 60 \% \leqq \text { canopy density } \leqq 80 \%\end{array}$ \\
\hline & $\begin{array}{l}\text { Riparian } \\
\text { shrub }\end{array}$ & $\begin{array}{l}\text { Tamarix ramosissima Ledeb, Sophora } \\
\text { alopecuroides L., Haloxylon ammodendron } \\
\text { (C.A.Mey.) Bunge and Phragmites australis (Cav.) } \\
\text { Trin. ex Steud, } 50 \% \leqq \text { vegetation coverage } \leqq 80 \%\end{array}$ \\
\hline & Water & $\begin{array}{l}\text { River, lake, reservoir, wetland and hydraulic } \\
\text { structure }\end{array}$ \\
\hline & Saline & Saline and alkaline land \\
\hline & Urban & Ejina county and artificial hills \\
\hline \multirow{4}{*}{ Desert } & Desert shrub & $\begin{array}{l}\text { Tamarix ramosissima Ledeb, Phragmites australis } \\
\text { (Cav.) Trin. ex Steud, Achnatherum splendens } \\
\text { (Trin.) Nevski, Glycyrrhiza glabra L., Sophora } \\
\text { alopecuroides L., } 30 \% \leqq \text { vegetation coverage } \leqq 50 \%\end{array}$ \\
\hline & $\begin{array}{l}\text { Desert } \\
\text { grassland }\end{array}$ & $\begin{array}{l}\text { Lycium ruthenicum Murr., Nitraria tangutorum } \\
\text { Bobr., Alhagi pseudalhagi Desv., Karelinia caspica } \\
\text { (Pall.) Less., Reaumuria soongorica (Pall.) Maxim., } \\
\text { vegetation coverage } \leqq 30 \%\end{array}$ \\
\hline & Gobi & Gobi desert \\
\hline & Sand & Moving sand dunes \\
\hline \multirow{2}{*}{ Others } & Hill & Low erosion hills \\
\hline & Dried lake & Dried West Juyan Lake \\
\hline
\end{tabular}

TABLE II. STATISTICS OF EJINA OASIS LANDSCAPE DURING 1987 2009 (HM²)

\begin{tabular}{c|l|cc|cc|cc}
\hline \multirow{2}{*}{ Class } & \multirow{2}{*}{$\begin{array}{c}\text { Landscape } \\
\text { Type }\end{array}$} & \multicolumn{2}{|c|}{$\mathbf{1 9 8 7 a}$} & \multicolumn{2}{|c|}{ 2001a } & \multicolumn{2}{c}{ 2009a } \\
\cline { 3 - 8 } & \multicolumn{1}{|c|}{ Area } & \% & Area & \% & Area & \% \\
\hline 1 & Riparian forest & 35418.42 & 2.11 & 19473.48 & 1.16 & 36671.76 & 2.19 \\
2 & Riparian shrub & 42938.19 & 2.56 & 57978.99 & 3.46 & 55188.72 & 3.29 \\
3 & Desert shrub & 73758.24 & 4.40 & 92848.50 & 5.54 & 76019.31 & 4.54 \\
4 & Desert grassland & 216189.45 & 12.90 & 184730.76 & 11.03 & 220225.77 & 13.14 \\
5 & Water & 2661.84 & 0.16 & 194.85 & 0.01 & 15616.71 & 0.93 \\
6 & Saline & 1272.60 & 0.08 & 225.36 & 0.01 & 191.43 & 0.01 \\
7 & Urban & 522.00 & 0.03 & 698.67 & 0.04 & 1354.23 & 0.08 \\
8 & Gobi & 1255743.0974 .95 & 1265445.45 & 75.53 & 1217945.3472 .69 \\
9 & Sand & 11442.06 & 0.68 & 18391.50 & 1.10 & 17253.63 & 1.03 \\
10 & Hill & 3852.63 & 0.23 & 3852.63 & 0.23 & 3852.63 & 0.23 \\
11 & Dried lake & 31649.40 & 1.89 & 31649.40 & 1.89 & 31173.39 & 1.86 \\
\hline
\end{tabular}

From this table we can see: the landscape of Gobi is the first primary class in this area covering over $70 \%$ of the total area; and the desert vegetation (i.e. Desert shrub and Desert grassland) is the second dominate class covering about $17 \%$ of the entire landscape; the area of the oasis vegetation (i.e. Riparian forest and Riparian shrub) is only taking up about 5\% of the total area; the water area is very small and only covering less than $1 \%$ of the total area.

Table III shows the statistics of changing area and ratio for Ejina oasis landscape from 1987 to 2009. Two stages were made for comparison. The first one is from 1987-2001 and the second one is from 2001-2009. For the first stage, one of the obvious change is from the oasis vegetation types, the riparian forest reduced by about $45 \%$, but the riparian shrub expanded by about $35 \%$; And for the desert vegetation types, the area of desert shrub increased by about $26 \%$ but the area of desert grassland shrank by about $15 \%$; The water area reduced by more than $90 \%$. But for the class of Gobi and sand, though they had only $0.77 \%$ and $60.74 \%$ increasing ratio respectively, their absolute areas increased about 9,700 and 6,900 square hectometer accordingly, these changes were huge for Ejina oasis during 1987 to 2001 .

TABLE III. CHANGING AREA AND RATIO OF EJINA OASIS DURING 1987 2009 $\left(\mathrm{HM}^{2}\right)$

\begin{tabular}{c|l|cc|cc}
\hline \multirow{2}{*}{ Class } & \multirow{2}{*}{ Landscape Type } & \multicolumn{2}{|c|}{ 1987-2001 } & \multicolumn{2}{c}{ 2001-2009 } \\
\cline { 3 - 6 } & & Change & \% & Change & \% \\
\hline 1 & Riparian forest & -15944.94 & -45.02 & 17198.28 & 88.32 \\
2 & Riparian shrub & 15040.80 & 35.03 & -2790.27 & -4.81 \\
3 & Desert shrub & 19090.26 & 25.88 & -16829.19 & -18.13 \\
4 & Desert grassland & -31458.69 & -14.55 & 35495.01 & 19.21 \\
5 & Water & -2466.99 & -92.68 & 15421.86 & 7914.73 \\
6 & Saline & -1047.24 & -82.29 & -33.93 & -15.06 \\
7 & Urban & 176.67 & 33.84 & 655.56 & 93.83 \\
8 & Gobi & 9702.36 & 0.77 & -47500.11 & -3.75 \\
9 & Sand & 6949.44 & 60.74 & -1137.87 & -6.19 \\
10 & Hill & 0.00 & 0.00 & 0.00 & 0.00 \\
11 & Dried lake & 0.00 & 0.00 & -476.01 & -1.50 \\
\hline
\end{tabular}

And for the second stage from 2001 to 2009, it seems that all the changes were in an opposite direction compared with the changes in the first stage. First, oasis vegetation of riparian forest expanded almost 90\% from 2001 to 2009. Second, water area increased by nearly 8,000 times. For the other oasis vegetation of riparian shrub, it had a little reduction by about $5 \%$. And for the desert vegetation, desert shrub reduced by about $18 \%$ and desert grassland increased by about $19 \%$. But, similarly, for the classes of Gobi and sand, though they only had about $4 \%$ and $6 \%$ decrease respectively, the absolute decrease area were about 47,500 and 1,138 square hectometer respectively. It was also great changes for Ejina oasis during this period.

Figure 2 is a histogram of landscape change ratio for Ejina oasis during 1987 to 2009 (Fig. 2). From this figure, we can obviously find that, except for the classes of decreasing saline and increasing urban, all other classes were changing in opposite direction during 1987-2001 and 2001-2009.

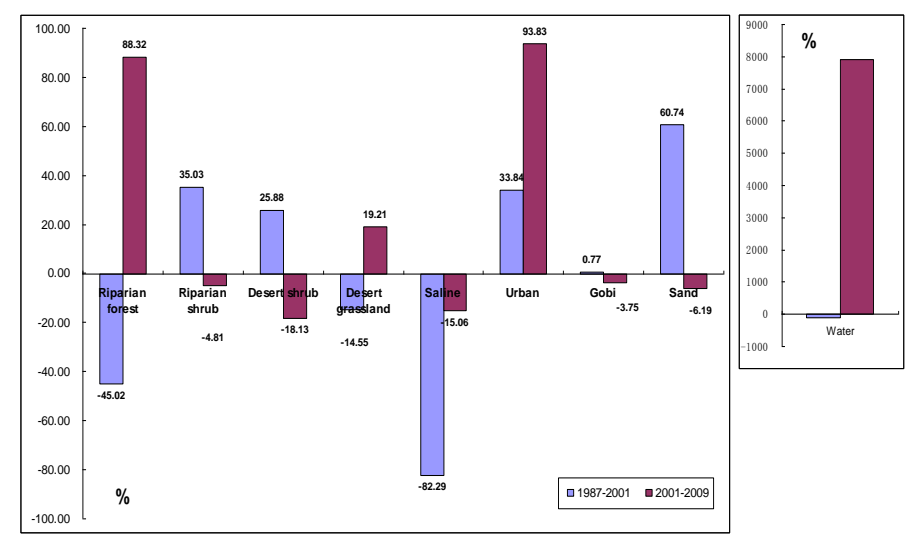

Fig. 2. Landscape change ratio of Ejina oasis during 1987 2009

\section{B. Landscape spatial pattern change}

Figure 3 shows how Ejina natural oasis landscape pattern was changing on spatial scale (Fig. 3). Among these changes, two of them should be noticed, one is the change from all other classes to oasis vegetation (riparian forest and riparian 
shrub), and the other is the change from all other classes to Gobi and sand, because these landscape classes are the key elements and sensitive indicators of ecological conditions for Ejina oasis. So we can make some general judgment from these two periods of landscape changes: Firstly, landscape changes from other classes to Gobi during 1987 to 2001 was greater than changes to oasis vegetation. Secondly, landscape changes from other classes to oasis vegetation during 2001 to 2009 was greater than changes to Gobi. Thirdly, changes to sand during 2001 2009 was obviously less than that during 1987 2001. Finally, landscape change spread all over the Ejina oasis, but mainly along the riparian zones of West and East Ejina river.
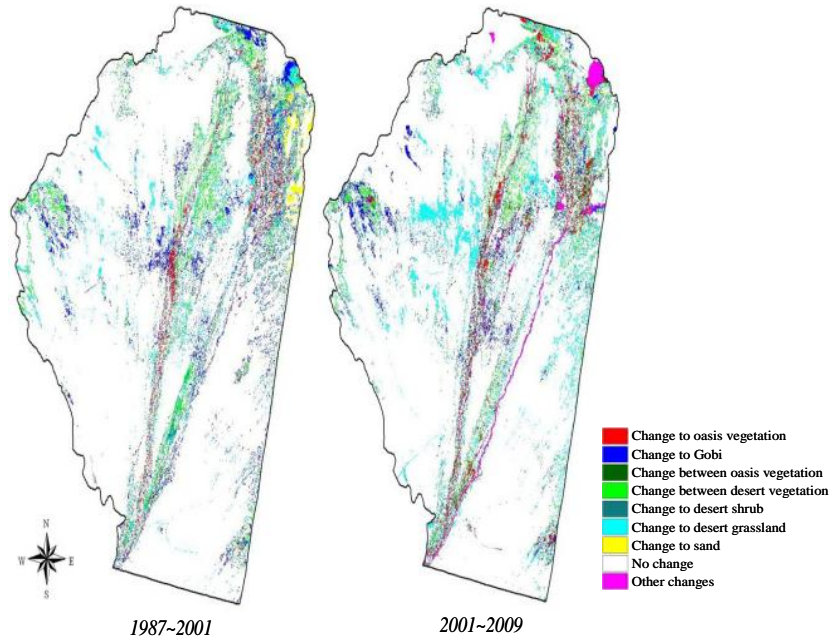

Fig. 3. Landscape spatial pattern change for Ejina oasis during 1987 2009

\section{Landscape metrics analysis}

Table IV and Fig. 4 show the statistics of landscape indices changes. From this table and figure we can see that all the landscape indices were also changing in an opposite direction for two different periods. Among these changes, the indices of Average patch area, Contagion and Dominance were increasing during 1987 2001 but were decreasing during 2001 to 2009. And the opposite changes could be observed from Edge density, Shannon-Weaver diversity and ShannonWeaver Evenness. All these changes show that before and after 2001, the landscape diversity and the landscape stability for Ejina oasis were quite different. Before 2001, the landscape diversity and landscape ecological stability became degraded, but after 2001, they got improved.

\section{General analysis of relationship between landscape change and surface water allocation}

Generally, all landscape changes have two kinds of driving forces, nature elements and human activities. Based on our previous research results, the hydrological factors are the most key driving force for the Ejina oasis landscape change, including surface water resource and ground water table ${ }^{[8]}$. The ground water table is mostly influenced by the surface runoff water. And the surface runoff water resource is finally influenced by human activities, such as increasing population, social and economic development, and water resource management. According to the statistical annual runoff data (1987 2009), the water resource management especially for the surface water allocation is the crucial factor for Ejina oasis landscape change during the past 20 years.

TABLE IV. STATISTICS OF LANDSCAPE INDICES CHANGE FOR EJINA OAISIS DURING 1987 2009

\begin{tabular}{lccccccc}
\hline $\begin{array}{c}\text { Landscape } \\
\text { index }\end{array}$ & $\mathbf{1 9 8 7}$ & $\mathbf{2 0 0 1}$ & $\mathbf{2 0 0 9}$ & $\mathbf{1 9 8 7} \mathbf{2 0 0 1}$ & $\boldsymbol{\%}$ & $\mathbf{2 0 0 1} \mathbf{2 0 0 9}$ & $\boldsymbol{\%}$ \\
\hline AA (hm2) & 53.76 & 61.37 & 55.22 & 7.61 & 14.16 & -6.15 & -10.02 \\
CO & 2.77 & 2.83 & 2.71 & 0.05 & 1.88 & -0.12 & -4.25 \\
DO & 1.46 & 1.47 & 1.38 & 0.01 & 0.48 & -0.09 & -6.33 \\
ED (m/hm2) & 41.38 & 35.58 & 37.59 & -5.80 & -14.01 & 2.01 & 5.64 \\
SWD & 0.94 & 0.93 & 1.02 & -0.01 & -0.64 & 0.09 & 10.02 \\
SWE & 0.40 & 0.39 & 0.43 & 0.01 & -0.77 & 0.04 & 10.08 \\
\hline
\end{tabular}

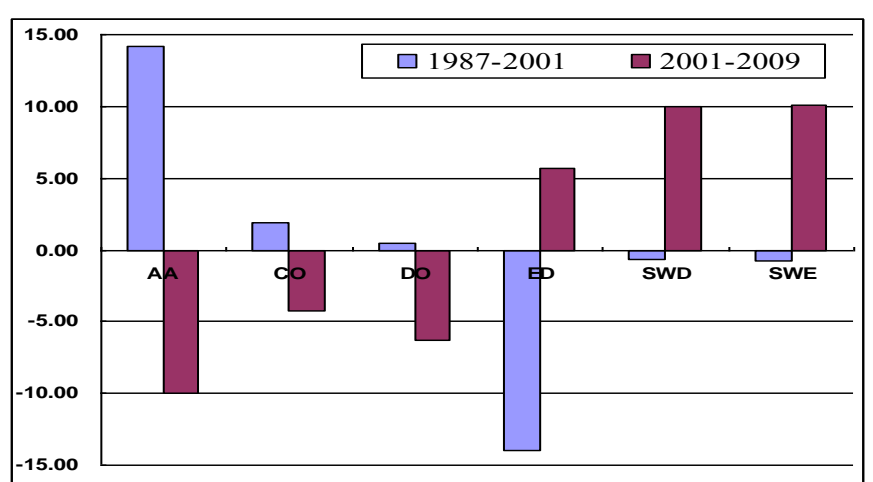

Fig. 4. Landscape indices change for Ejina oasis during 1987 2009

\section{CONCLUSIONS}

Before and after water allocated in Ejina oasis, the classes of oasis landscape type decreased during 1987-2001 and increased during 2001-2009, but at the same time, the classes of desert landscape type changed to an inverse direction. Moreover, landscape diversity and ecological stability for Ejina oasis after water allocated was much higher than before water allocated. And finally, Ejina oasis landscape spatial pattern changes were generally related to surface runoff water allocation in the whole Heihe river basin.

\section{REFERENCES}

[1] P. J. Crutzen, "Geology of mankind: The Anthropocene," Nature, vol. 415, pp. 23, January 2002.

[2] Z. Naveh, "What is holistic landscape ecology? A conceptual introduction," Landscape Urban Plan., vol. 50, pp. 7-26, August 2000.

[3] G. Tress, B. Tress, G. Fry, "Clarifying integrative research concepts in landscape ecology," Landscape Ecol., vol. 20(4), pp. 479-493, May 2005.

[4] M. G. Turner, "Disturbance and landscape dynamics in a changing world," Ecology, vol. 91(10), pp. 2833-2849, October 2010.

[5] J. Wu, R. Hobbs, Key Topics in Landscape Ecology. Cambridge: Cambridge University Press, 2006.

[6] Y. Cao, H. Ouyang, D. N. Xiao, G. Chen, "Landscape change and its eco-environmental effects in Ejin natural oasis," vol. 24(1), pp. 130-139, January 2005. 